\title{
Histopathological subtypes and demographic profile of cystic jaw lesions - A hospital based study
}

\author{
Arnab Ghosh ${ }^{1}$, Dilasma Gharti Magar ${ }^{1}$, Sushma Thapa ${ }^{1}$, Om Prakash Talwar ${ }^{1}$ \\ ${ }^{\prime}$ Department of Pathology, Manipal Teaching Hospital, Manipal College of Medical sciences, Pokhara, Nepal.
}

\section{Keywords: \\ Cyst; \\ Dentigerous; \\ Jaw; \\ Keratocyst; \\ Odontogenic; \\ Radicular;}

\begin{abstract}
Background: Odontogenic cysts are defined as the epithelial cysts which arise from odontogenic epithelium and occur in tooth bearing regions of jaws. The objective of the present study was to analyze different histopathological types of cystic jaw lesions and to determine the distribution of their relative frequency according to site, sex, size and age group.

Materials and Methods: This study was a cross sectional hospital based observational study conducted in the Department of Pathology, Manipal Teaching Hospital. All cases with cystic jaw lesions on histopathology during the study period from January 2014 to December 2018 were included in the study.

Results: Thirty-two cases of cystic jaw lesions were reported during the study period. Females were more commonly affected in our study with a male: female ratio of 1:1.9. The age range in the study was 9 to 71 years with a mean age of 33.3 years. The most frequent type was radicular cysts followed by dentigerous cysts, odontogenic keratocysts and cystic ameloblastoma. Radicular cysts showed the most female predilection with a ratio of 1:4.3. and a mean age of 35.6 years. Majority of dentigerous cysts were seen in patients below 30 years. Both radicular cysts and dentigerous cysts showed more involvement of maxilla but odontogenic keratocysts were more common in mandible.
\end{abstract}

Conclusion: The present study corroborate with other similar literature with respect to the frequency percentage of different types of jaw cysts.However, female predilection was seen in radicular and dentigerous cysts. Maxilla was the more common site except in odontogenic keratocysts.

\section{Correspondence:}

Dr. Arnab Ghosh, MD

Department of Pathology

Manipal College of Medical Sciences, Pokhara Nepal.

ORCID ID: 0000-0002-8566-2067

Email:docarnab2k@yahoo.com

Received : January $4^{\text {th }} 2019 ;$ Accepted : March $2^{\text {nd }} 2019 ;$ Published : March $29^{\text {th }} 2019$

Citation: Ghosh A, Gharti Magar D, Thapa S, Talwar OP. Histopathological subtypes and demographic profile of Cystic jaw lesions - A hospital based study. J Pathol. Nep 2019;9:1445-9. DOI: 10.3126/jpn. v9i1.23152

Copyright: This is an open-access article distributed under the terms of the Creative Commons Attribution 4.0 International License, which permits unrestricted use, distribution, and reproduction in any medium, provided the original author and source are credited.

\section{INTRODUCTION}

Cystic lesions can occur in jaw bones and have been classified in several ways according to different criteria, e.g., embryologic origin, etiology, clinical and morphological features. A true or epithelial cyst is defined as a cavity which is completely or partly lined by an epithelial lining containing fluid or semi fluid substance. The World Health Organization (WHO) has classified the epithelial cysts in jaw into odontogenic and non-odontogenic cysts. ${ }^{1}$ Odontogenic cysts are defined as the epithelial cysts which arise from odontogenic epithelium and occur in tooth bearing regions of jaws. Despite the large number of studies on odontogenic cysts in the literature, information regarding 
Table 1: Frequency, percentage and sex distribution of different histological types of jaw cysts $(n=32)$

\begin{tabular}{|c|c|c|c|c|c|}
\hline Histopathological types & Cases (n) & $\%$ & Male & Female & M:F ratio \\
\hline Radicular cyst & 16 & 50 & 3 & 13 & $1: 4.3$ \\
\hline Dentigerous cyst & 11 & 34.4 & 5 & 6 & $1: 1.2$ \\
\hline Odontogenic keratocyst & 4 & 12.5 & 2 & 2 & $1: 1$ \\
\hline Cystic ameloblastoma & 1 & 3.1 & 1 & - & - \\
\hline Total & 32 & 100 & 11 & 21 & 1:1.9 \\
\hline
\end{tabular}

Table 2: Age distribution and mean age of different histological types of jaw cysts $(n=32)$

\begin{tabular}{|c|c|c|c|c|c|c|c|c|c|c|}
\hline \multirow{2}{*}{ Histopathological types } & \multirow{2}{*}{ Cases (n) } & \multirow{2}{*}{ Mean age } & \multicolumn{8}{|c|}{ Age groups ( years) } \\
\hline & & & $<10$ & $11-20$ & $21-30$ & $31-40$ & $41-50$ & $51-60$ & $61-70$ & $>71$ \\
\hline Radicular cyst & 16 & 35.6 & - & 3 & 4 & 3 & 2 & 4 & - & - \\
\hline Dentigerous cyst & 11 & 32.6 & 1 & 5 & 2 & - & - & 1 & 1 & 1 \\
\hline Odontogenic keratocyst & 4 & 39 & - & 1 & 1 & 1 & - & - & 1 & - \\
\hline Cystic ameloblastoma & 1 & 15 & - & 1 & - & - & - & - & - & - \\
\hline Total & 32 & 33.3 & 1 & 10 & 7 & 4 & 2 & 5 & 2 & 1 \\
\hline
\end{tabular}

Table 3: Side, site and size distribution of different histological types of jaw cysts $(n=32)$

\begin{tabular}{|c|c|c|c|c|c|c|}
\hline \multirow[t]{2}{*}{ Histopathological types } & \multirow[t]{2}{*}{ Cases (n) } & \multicolumn{2}{|c|}{ Side } & \multicolumn{2}{|c|}{ Site } & \multirow[t]{2}{*}{ Mean diameter } \\
\hline & & Left & Right & Maxilla & Mandible & \\
\hline Radicular cyst & 16 & 7 & 9 & 11 & 5 & $2.3 \mathrm{~cm}$ \\
\hline Dentigerous cyst & 11 & 7 & 4 & 8 & 3 & $3.2 \mathrm{~cm}$ \\
\hline Odontogenic keratocyst & 4 & 1 & 3 & 1 & 3 & $2.8 \mathrm{~cm}$ \\
\hline Cystic ameloblastoma & 1 & & 1 & - & 1 & $3 \mathrm{~cm}$ \\
\hline Total & 32 & 15 & 17 & 20 & 12 & \\
\hline
\end{tabular}

the demographic profile of these lesions are limited and varying. ${ }^{2,3}$ The objective of the present study was to analyze different histopathological types of cystic jaw lesions and to determine the distribution of their relative frequency according to sex , age, site and size.$^{2}$

\section{MATERIAL AND METHODS}

This study was a cross sectional hospital based observational study conducted in the Department of Pathology, Manipal Teaching Hospital. All cases diagnosed with cystic jaw lesions on histopathology during the study period from January 2014 to December 2018 were included in the study. The tissue bits received were routinely fixed in $10 \%$ buffered formalin. The bony bits were chemically decalcified before processing. The tissues were routinely stained with hematoxylin and eosin stain. Diagnosis was made by consultant Pathologists. The data collected was analyzed with the software SPSS v16. Approval from the institutional ethical committee was taken and the study was conducted in accordance with the Helsinki Declaration.

\section{RESULTS}

A total of 32 cases of cystic jaw lesions were reported during the study period. The most frequent type was radicular cysts comprising 16 cases followed by dentigerous cysts, odontogenic keratocysts and cystic ameloblastoma. ( Table 1 ) Females were more commonly affected in our study with a male: female ratio of $1: 1.9$. Radicular cysts showed the maximum female predilection with a sex ratio of $1: 4.3$. The age range in our study was 9 to 71 years with a mean age of 33.3 years. The age distribution and the mean age of all the different subtypes have been shown in Table 2 . The age range in patients with radicular cyst was 18 to 55 years and that with dentigerous cysts were 9 to 71 years. Majority of the dentigrous cysts $(8 / 11,72.7 \%)$ were seen in cases below 30 years. Out of 4 cases of odontogenic keratocysts, 3 cases were between 18 and 36 years while 1 case was 70 years old. We had only 1 case of cystic ameloblastoma which was seen in the mandible of a 15 year old boy. The site of the lesion including the affected side, upper or lower jaw and the mean size of all the types have been summarized in Table 3 .

No significant predilection to site affected was observed, however, maxilla was involved more often than mandible. Both radicular cysts and dentigerous cysts showed more involvement of maxilla. However among 4 cases of odontogenic keratocysts, 3 were in the angle of right mandible and 1 case was in left maxilla. The only case of cystic ameloblastoma was close to the lower right $3^{\text {rd }}$ molar. The mean diameter of the dentigerous cysts was the largest 
followed by odontogenic keratocysts, cystic ameloblastoma and radicular cysts. (Table 3 )

All cases with odontogenic keratocysts and cystic ameloblastoma showed multiloculated cysts and all radicular and dentigerous cysts showed unilocular cysts on Xray.

\section{DISCUSSION}

Jaw cysts may have developmental, inflammatory or neoplastic etiology and may be seen in pediatric as well as in adult age groups. Embryogenesis of teeth in fetal life is a complex process and may cause persistence of remnants of cell rests of different types which eventually may develop into cysts. In children, developmental processes including odontogenesis of the deciduous and permanent teeth take place in the jaws which may be related with cyst formation. While in adults, the permanent dentition may be damaged due to trauma, caries and aging, which may be associated with formation of cysts. . $^{1,2,-6}$

Odontogenic cysts can affect patients with wide age range. ${ }^{1}$ Considering all the 32 cases in the current study, the commonest affected age group was $11-20$ years with a mean age of 33.3 years. Selvamani M and Kamrujjaman M et al in their studies analyzed 153 and 62 cases and found that the commonest affected age group was 11-20 and 2030 years respectively. ${ }^{3,4}$ In different studies on cystic jaw lesions by Kamrujjaman $\mathrm{M}$ et $\mathrm{al}^{4}$, Monteiro L et $\mathrm{al}^{7}$, Rao K et $\mathrm{al}^{8}$, Urrutia-Nunez $\mathrm{S}$ et $\mathrm{al}^{9}$, Avelar RL et $\mathrm{al}^{10}$ and Aleem B et $\mathrm{al}^{11}$, the mean ages were 28.06, 34.0, 42.0, 42.0, 28.9 and 29.6 years respectively.

Analyzing the sex ratio of all the cases in our study, there was a considerable female preponderance with the male to female ratio of 1:1.9. Interestingly, in similar other studies, the sex predilection was only marginal and was also variable. In some studies females were slightly more affected with the male to female ratios of 1:1.06 $, 1: 1.08^{8}$, while in other studies, male patients were more commonly encountered with the sex ratio being 1.1:19, $1.4: 1^{10}, 1.3: 1^{12}$. Overall, the maxilla was more commonly affected by odontogenic cysts than mandible in our study which was in concordance with studies done by Selvamani M et al., Ochsenius G et al., Prockt AP et al., and Varinauskas V et al. ${ }^{3,13-15}$ However, in a large study of 695 cases of odontogenic cysts by Meningaud JP et al., mandible was three times more affected than maxilla. ${ }^{16}$

The odontogenic cysts can broadly be classified into inflammatory, developmental and neoplastic types. Inflammatory cysts are due to an infection of the tooth or dental caries which may further cause necrosis of the pulp cavity and thus the infection may spread towards the apex and root of the tooth. As a result, abscesses are formed in the periapical area which subsequently may lead to the formation of radicular or periapical cysts, the commonest type of inflammatory cysts. There are different proposed theories regarding the exact mechanism for formation of the radicular cysts. One theory suggests proliferation of epithelial cell rest of periodontal ligament ( Cell rest of Malassez) as a reaction to the ongoing inflammation. The other proposed pathogenesis suggests that after the removal of necro-inflammatory content by pathologic processes, the periapical abscess leads to the formation of a radicular cyst. On the other hand, developmental cysts include those originating from enamel organ remnant, dental lamina and keratotic cysts. Commonest type of developmental cysts are dentigerous cysts which are formed due to accumulation of fluid between remnant of enamel organ and tooth crown. Its cyst wall is typically attached to the neck of an unerupted tooth. $., 5,6,17$

The frequency distribution of the different types of jaw cysts in general population indicates that the radicular cyst is the most frequent type (56\%) followed by dentigerous cyst $(17 \%))^{18,19}$ While comparing the frequencies in the general population with that of the present study, radicular cyst showed almost similar percentage $(50 \%)$ and was the commonest type but the percentage of dentigerous cyst was much higher (34.4\%) in our data.

Radicular cysts are the most frequent type comprising majority of the cases in all other similar studies except one by Aleem B et al who found odontogenic keratocyst to be the commonest entity. ${ }^{11}$ However, different authors have reported varying percentages of radicular cysts in their series viz., $48 \%^{2}, 69.3 \%^{3}, 56 \%^{4}, 35 \%{ }^{11}, 56.9 \%{ }^{12}, 72.5 \%^{14}$, $53.5 \%{ }^{16}$ and $60.3 \%{ }^{20}$. Among the 16 cases of radicular cysts in our analysis, females were 4.3 times more commonly affected than males. In contrast, the studies which have reported female predilection in radicular cysts reported only $1.1^{3}, 1.07^{13}, 1.6^{14}$ and $1.27^{21}$ times more involvement of females while a few studies have reported male predilection. ${ }^{12,16,20}$ The commonest affected age group was 21-30 years in the present study which was similar to the studies by Kamrujjaman $\mathrm{M}$ et al and Ochsenius $\mathrm{G}$ et al. ${ }^{4,13}$ All of our cases were in the age groups 11 to 60 years with a mean age of 35.6 years. In the study by Meningaud JP et al., the mean age was 40.8 years. ${ }^{16}$ Maxilla was more commonly affected in our study which was similar to most other literatures. ${ }^{1,3}$

As it was noted in the present study, several other authors also found that the dentigerous cysts were the second most common odontogenic cysts and the commonest type of developmental cysts. ${ }^{2,13,16}$ They comprised $34.4 \%$ of all cases in our study while the frequency varies from 11.4 to $44 \%$ in other studies. ${ }^{3,13}$ In most of the studies, males were reported to be more commonly affected than females. ${ }^{12,13,16,21,22}$ But, in the study by Prokt AP et al. and in the current study, 
females comprised $52 \%$ and $54.5 \%$ of all dentigerous cysts respectively. ${ }^{14}$ Dentigerous cysts are mostly seen in the first and second decades of life. ${ }^{12,13,21}$ In the present data, $45 \%$ dentigerous cysts were in the age group 11-20 years. Considering the sites affected by dentigerous cysts in other series, it was noted the posterior part of the mandible was the commonest site followed by the maxilla. ${ }^{12,14,20} \mathrm{In}$ contrast, maxilla was the more affected site in our study.

The third most common entity in our study was odontogenic keratocyst. In most of the similar literature on odontogenic cysts, odontogenic keratocysts were included in the study as it used to be classified as odontogenic cysts arising from the remnants of the dental lamina. However, they are known to have a marked tendency to recur, are clinically aggressive, show high mitotic count and high Ki67 index. They also may have genetic association with Gorlin-Goltz syndrome (nevoid basal cell carcinoma syndrome). In view of these features, the WHO in 2005 reclassified odontogenic keratocysts as keratocystic odontogenic tumors. ${ }^{3,5,6,14} \mathrm{We}$ had only 4 cases comprising $12.5 \%$ of all cases which is similar to Monterio L et al.(12.1\%), and Ochsenius G et al. $(14.3 \%))^{7,13}$ However, in different studies the percentages of odontogenic keratocysts varied widely between $1 \%$ to as high as $50 \%{ }^{9,11}$ Males are known to be more commonly affected. ${ }^{22}$ In the present study, however, both sexes were equally affected. Posterior part of mandible is the most commonly affected site. ${ }^{5}$ This is similar to our study as we found $75 \%$ of the keratocysts occurred in the angle of mandible. None of our cases had clinical features of GorlinGoltz syndrome.

\section{CONCLUSION}

The present study corroborate with other similar literature with respect to the frequency percentage of different types of jaw cysts as the radicular cysts were the commonest type followed by the dentigerous cysts. We found overall female predilection especially in radicular cysts which was unlike most other studies. Age of the affected patients varied widely in different studies. Maxilla was affected more frequently in our study except in the cases with odontogenic keratocyst where posterior part of mandible was more involved.

\section{Conflict of interest: None}

\section{REFERENCES}

1. Neville BW, Damm DD, Allen CM, Chi AC. Odontogenic cysts and tumors. In: Oral and Maxillofacial Pathology. 4th ed. St Louis: Elsevier; 2016. pp 632-89.

2. Manor E, Kachko L, Puterman BM, Szabo G, Bodner L. Cystic lesions of the jaws - a clinicopathological study of 322 cases and review of the literature. Int J Med Sci. 2012;9:20-6. https://doi. org/10.7150/ijms. 9.20
3. Selvamani M, Donoghue M, Basandi PS. Analysis of 153 cases of odontogenic cysts in a South Indian sample population: a retrospective study over a decade. Brazilian oral research. 2012;26:330-4. https:// doi.org/10.1590/S1806-83242012005000007

4. Kamrujjaman M, Hasan S, Khan AD, Noor H, Hasnat A. Clinicopathological Evaluation of Odontogenic Jaw Cysts. Update Dent. Coll. J. 2015; :30-9.

5. Soames JV, Southam JC. Cysts of the jaws and oral soft tissues. In: Oral Pathology. 4th ed. New York: Oxford University Press; 2005. pp65-84.

6. Philipsen HP. Keratocystic odontogenic tumour. In: Barnes EL, Eveson JW, Reichart P, Sidransky D, editors. World Health Organization Classification of Tumours: pathology and genetics of head and neck tumours. Lyon, France: IARC Press; 2005.pp306-7.

7. Monteiro L, Pe-a J, Fonseca L, Paiva A, Amaral B. Odontogenic cysts - a descriptive clinicopathological study. Braz J Oral Sci. 2005;4:670-5.

8. Rao K, Smitha, Umadevi HS,Priya NS. Clinicopathological studyof 100 Odontogenic cysts reported atV S Dental College- A Retrospective Study. J. Adv Dental Research. 2011;2:51-8.

9. Nunez-Urrutia S, Figueiredo R, Gay-Escoda C. Retrospective clinicopathological study of 418 odontogenic cysts. Med Oral Patol Oral Cir Bucal. 2010;15:e767-73. https://doi.org/10.4317/ medoral.15.e767

10. Avelar RL, Antunes AA, Carvalho RW, Bezerra PG, Neto PJ, Andrade ES. Odontogenic cysts: a clinicopathological study of 507 cases. J Oral Sci. 2009;51:581-6. https://doi.org/10.2334/josnusd.51.581

11. Aleem B, Hussain A, Anwar S, Anjum R. Distribution of Odontogenic Cyst in a Tertiary Care Hospital, Over a Period of One Year. Pakistan Journal Medical Health \& Science. 2017;11:1209-10.

12. Koseoglu BG, Atalay B, Erdem MA. Odontogenic cysts: a clinical study of 90 cases. J Oral Sci. 2004;46:253-7. https://doi.org/10.2334/ josnusd. 46.253

13. Ochsenius G, Escobar E, Godoy L, Pe-afiel C. Odontogenic cysts: analysis of 2,944 cases in Chile. Med Oral Patol Oral Cir Bucal. 2007;12:e85-91. PMID:17322811

14. Prockt AP, Schebela CR, Maito FD, Sant'Ana-Filho M, Rados PV. Odontogenic cysts: analysis of 680 cases in Brazil. Head Neck Pathol. 2008;2:150-6. https://doi.org/10.1007/s12105-008-0060-7

15. Varinauskas V, Gervickas A, Kavoliu niene O. Analysis of odontogenic cysts of the jaws. Medicina (Kaunas). 2006;42:201-7.

16. Meningaud JP, Oprean N, Pitak-Arnnop P, Bertrand JC. Odontogenic cysts: a clinical study of 695 cases. J Oral Sci. 2006;48:59-62. https:// doi.org/10.2334/josnusd. 48.59 
17. Janardhanam D, Sahuthullah Y, Nalliappan G, Shivakumar S. Radiological and Pathological Characteristics of Mandibular Cystic Lesion - A Review. IOSR Journal of Dental and Medical Sciences. 2016;15:74-80. https://doi.org/10.9790/0853-1509107480

18. Killy HC, Kay LW. An analysis of 471 benign cystic lesions of the jaws. Int Surg. 1966;46:540-5.

19. Shear M, Singh S. Classification and frequency of cysts of the oral and maxillofacial tissues. In: Shear M, Speight P, editors. Cysts of the oral and maxillofacial regions. 4th ed. Oxford: Blackwell Munksgaard; 2007. https://doi.org/10.1002/9780470759769.ch1

20. Jones AV, Craig GT, Franklin CD. Range and demographics of odontogenic cysts diagnosed in a UK population over a 30 -year period. J Oral Pathol Med. 2006;35:500-7. https://doi.org/10.1111/ j.1600-0714.2006.00455.x

21. Ledesma-Montes C, Hernández-Guerrero JC, Garcés-Ortíz M. Clinico-pathologic study of odontogenic cysts in a Mexican sample population. Arch Med Res. 2000;31:373-6. https://doi.org/10.1016/ S0188-4409(00)00069-2

22. Mosqueda-Taylor A, Irigoyen-Camacho ME, Diaz-Franco MA, Torres-Tejero MA. Odontogenic cysts: analysis of 856 cases. Med Oral. 2002;7:89-96. PMID:11887015 